\title{
A CRISE DA SUBJETIVIDADE E O DESPONTAR DAS PSICOLOGIAS FENOMENOLÓGICAS
}

\author{
Ana Maria Lopez Calvo de Feijoo*
}

\begin{abstract}
RESUMO. Pretende-se aqui discutir como os fundamentos da metafísica da subjetividade (tais como a concepção do eu nuclear e a dicotomização entre interioridade e totalidade) foram hegemônicos na constituição de boa parte das teorias e práticas psicológicas. Apontando para as contradições e para o consequente esvaziamento que a premissa da subjetividade e a dicotomização da totalidade impuseram à Psicologia, lançaremos as bases de uma psicologia fenomenológico-existencial voltada para o social que, embasando-se na Fenomenologia e na Filosofia da Existência, possa romper com a posição substancialista e dicotômica assumida pelos diferentes modelos em Psicologia. Para tanto, tomar-se-á a proposta fenomenológica inaugurada por Husserl e levada adiante por Heidegger, para pensar o eu como um fluxo de vivências intencionais fundadas na imanência de uma consciência já sempre projetada para além de si ou como um campo existencial de sentido e significados compartilhados assentado na temporalidade do ser-aí.
\end{abstract}

Palavras-chave: Subjetividade; fenomenologia; filosofia da existência.

\section{SUBJECTIVITY CRISIS AND THE EMERGING OF PHENOMENOLOGICAL PSYCHOLOGIES}

\begin{abstract}
This paper intents to discuss how the bases of subjectivity metaphysics were hegemonic in constituting most of the psychologic theories and practice. Pointing to the contradictions and consequent emptiness that the premise of subjectivity as well as the dichotomization of totality imposed to Psychology, we will launch the bases of a Phenomenological-Existential Psychology turned to the social that, based on Phenomenology and in the Existence Philosophy, will be able to rupture the substantialist and dichotomic position used by various different models in Psychology. For that, we will take the phenomenological proposal, inaugurated by Husserl and carried ahead by Heidegger, to think about the self as a flux of intentional living experiences based on the immanency of a consciousness already projected to beyond itself or as an existential field with senses and meanings shared and based on the temporality of the "be-here".
\end{abstract}

Key words: Subjectivity; phenomenology; existence philosophy.

\section{LA CRISIS DE LA SUBJETIVIDAD: DESPUNTAR DE LAS PSICOLOGÍAS FENOMENOLÓGICAS}

\begin{abstract}
RESUMEN. Aquí se pretende discutir como los fundamentos de la metafísica de la subjetividad fueran hegemónicos en la constitución de buena parte de las teorías y prácticas psicológicas. Apuntando a las contradicciones y el consecuente desvanecimiento que la premisa de la subjetividad y la dicotomización de la totalidad, impusieran a la Psicología , lanzaremos las bases de una Psicología Fenomenológico-Existencial volcada al ámbito social, que basándose en la Fenomenología y en la Filosofía de la Existencia, pueda romper con la posición sustancialista y dicotómica asumida por los diferentes modelos en Psicología. Por lo tanto , tómese la propuesta fenomenológica de Husserl y llevada a delante por Heidegger, para pensar el yo como una corriente de vivencias intencionales basada en la inmanencia de una conciencia que siempre ha proyectado más allá de si misma o como un campo existencial de sentidos y significados compartidos asentados en la temporalidad del ser.
\end{abstract}

Palabras-clave: Subjetividad; fenomenología , filosofía de la existencia.

Iniciaremos por discutir até que ponto as filosofias da subjetividade, com a concepção que lhes é comum do sujeito que pensa a si mesmo como contraposto ao objeto, embasam boa parte das concepções teóricas e

Doutora em Psicoterapias Atuais pela Universidade Federal do Rio de Janeiro. Pós-Doutorado em Filosofia na UFRJ. Professora Adjunta do curso de Psicologia e da Pós-Graduação em Psicologia Social da Universidade Federal do Rio de Janeiro. 
práticas em Psicologia, assim como tendem, subsequentemente, a promover a desconsideração do horizonte social mais amplo, a partir do qual são originariamente possíveis todas as determinações do homem. A Psicologia, de modo geral, parte da referência a um eu que, além de posicionar os objetos no mundo, constitui-se como substância localizável no tempo e no espaço, portanto, dotada de determinações e sentidos dados. Esta concepção de sujeito nuclear tornou-se a tendência praticamente hegemônica na fundamentação das teorias e das práticas em Psicologia. Desta forma, as psicologias passaram muitas vezes a elaborar verdadeiras cartografias acerca do eu, fundamentadas por teorias nem sempre consistentemente construídas.

A abrangência que as filosofias da subjetividade tomaram na Psicologia acabou por levar a um total abandono do horizonte de constituição do social, do político e da cultura. Presas à noção de sujeito, essas filosofias desconsideraram na fonte a articulação primeira entre o homem e o mundo. Essa desconsideração não aconteceu de maneira genérica e indeterminada, mas seguiu inicialmente duas vias específicas, sem comentar mais detidamente os problemas relativos ao acesso a essa subjetividade pura e universal, problemas tão densamente tratados por Friedrich Nietzsche. As teorias construídas no âmbito da subjetividade jamais conseguem se livrar da suspeita de um falseamento dos fenômenos. Por mais bem-fundamentada que pareçam as teorias ligadas à subjetividade, sempre padecem de uma suspeita quanto à sua consistência última. Teorias, na medida em que sempre se constroem com base em pressupostos, contam incessantemente com certa dose de crença. É isso que sentimos, por exemplo, diante das teorias dedutivas em geral. Por outro lado, há a possibilidade de corrigir esse caráter inconsistente das teorias do eu por meio de um apoio mais efetivo nas ciências empíricas. Temos, com isso, o surgimento de teorias que vão se estruturar a partir de uma perspectiva positivista. Neste caso, passa a ser considerado como a verdade sobre o psiquismo aquilo que se apresenta como passível de comprovação empírica, agora denominado comportamento ou rede de comportamentos. O problema dessa concepção, não obstante, é o pressuposto, também questionável, da estrutura biológica, orgânica, do psiquismo humano, o qual retém a noção de subjetividade em sintonia com a estrutura comportamental. Ora, o quê nos permite falar em uma desconsideração da relação primeira entre homem e mundo? Qual a base de tal relação? A necessidade de responder a essas perguntas é o que orienta primariamente nossa discussão; todavia, antes de explicitarmos um pouco mais como uma resposta pode ser alcançada, é preciso ter em vista um último ponto crítico.

A própria filosofia vem anunciando, desde o final do século XIX, uma crise com relação às filosofias da subjetividade, que se mostraram a partir de certo momento como insuficientes diante da complexidade da existência humana. Tal crítica foi absorvida pela psicologia existencial-humanista. Como a crítica filosófica à subjetividade, as psicologias existencialhumanistas também se opunham ao pressuposto do sujeito, seja como aparato psíquico, seja como unidade comportamental, passando a denominá-lo de pessoa, a fim de, desta forma, devolver-lhe a dignidade. Constata-se, por outro lado, que estas correntes, mesmo apontando para uma tentativa de se articular de modo diferenciado das demais, acabaram por recair na mesma noção de sujeito que criticavam e por manter os mesmos referenciais idealizados pelas psicologias primeiras (Behaviorismo e Psicanálise), as quais, com suas respectivas técnicas, visavam a produzir um maior conhecimento de si mesmo e estabeleciam um ideal psíquico a ser atingido. Ao mesmo tempo, a perspectiva existencial-humanista ainda mantém a Psicologia como disciplina cujo interesse se encontra no âmbito meramente privado.

Dito de maneira mais explícita: ela também desconsidera o horizonte mundano-relacional de todas as possibilidades existenciais humanas. Nossa questão se recoloca, então, uma vez mais: o que pode nos servir de base para uma superação desse que nos parece ser um efeito fatídico da filosofia moderna sobre a Psicologia? Uma vez esclarecida a crise das referências que articulam as psicologias modernas, buscaremos na Fenomenologia de Husserl e na ontologia fenomenológico-existencial de Heidegger fundamentos para repensar uma proposta em Psicologia (fenomenológico-existencial) que, respectivamente, trabalhe com as noções de intencionalidade e de poder-ser, de modo a apresentar uma nova compreensão dos fenômenos psíquicos em geral. Essa busca repercute diretamente sobre a Psicologia Social, uma vez que a fenomenologia, tanto em Husserl quanto em Heidegger, pensa o homem como marcado por uma estrutura que inviabiliza na raiz todo e qualquer solipsismo e que o projeta diretamente para uma relação com os outros e com o mundo. Nossa hipótese é que a fenomenologia traz consigo uma possibilidade de transformação da psicologia, uma vez que vê os fenômenos psicossociais como estruturados a partir da relação originária homem-mundo. 
Boss (1976) esclarece que a articulação da fenomenologia de Husserl e Heidegger, sobretudo da de Heidegger, com a Psicologia e com a Psiquiatria foi inaugurada na década de quarenta do século passado, quando o psiquiatra suíço Ludwig Binswanger utilizou o termo Daseinsanalyse pela primeira vez para designar uma abordagem que, baseada no filósofo alemão, diferenciava-se de duas referências essenciais nas ciências naturais: o determinismo causal aplicado à existência humana e a suposição de que forças e complexos psíquicos agem de modo oculto nas expressões aparentes do homem. Por outro lado, ao reconhecer que sua perspectiva ainda se mantinha na ideia de uma subjetividade fechada em si mesma e dotada da possibilidade de se relacionar eticamente com os outros a partir da empatia, Binswanger acaba por constituir uma psicologia com base no amor; logo também mantendo a sua perspectiva em uma discussão no âmbito do particular, Heidegger acusa Binswanger de permanecer em uma psicologia que se aproximava mais da posição com ênfase na filosofia da subjetividade. O psiquiatra passa, então, a denominar a sua abordagem de "Fenomenologia Antropológica" e a retomar uma proximidade maior com Husserl. A Daseinsanalyse, porém, voltou a ser discutida nos encontros regulares de Medard Boss com Heidegger e outros médicos e psicoterapeutas, publicados com o título de Seminários de Zollikon (Heidegger, 1987/2001). Nesses seminários, que aconteceram de 1959 a 1969, abriram-se outras possibilidades de discussão e de reflexão sobre a verdade, o tempo, o espaço e a causalidade. Embora Heidegger tenha abalizado a proposta da Daseinsanalyse de Boss, esta não foi incluída no contexto da Psicologia de forma ampla, mantendo-se apenas em grupos muito restritos. Assim, um dos principais objetivos do presente artigo é justamente corrigir esse fato, explorando possibilidades intrínsecas a uma psicologia com ênfase no social, pois, como afirma Charles Taylor (1997) em sua contribuição sobre Heidegger, esse filósofo é efetivamente um filósofo social.

Neste trabalho pretendemos ampliar e divulgar os fundamentos de uma psicologia que, a partir do pensamento de Husserl, coloque-se em sintonia com elementos insinuados na ontologia de Heidegger, mas não desenvolvidos no âmbito da Psicologia. Ao se alterar a concepção de eu e, consequentemente, a atitude diante do fenômeno, passa-se a estabelecer uma nova articulação para a Psicologia, partindo-se do pressuposto de que toda e qualquer teoria não fenomenológica acerca da existência humana deve ser suspensa para que possamos nos aproximar do fenômeno que se pretenda investigar.

\section{GÊNESE E DESENVOLVIMENTO DA MODERNA FILOSOFIA DA SUBJETIVIDADE}

Apresentaremos de maneira sintética as elaborações acerca da subjetividade no âmbito da Filosofia moderna (Descartes) para então podermos mostrar como as psicologias modernas vão estabelecer uma teoria e prática a partir da concepção de subjetividade. Primeiramente, iremos reconstruir a concepção cartesiana da subjetividade moderna: sua gênese e seu desenvolvimento. Para tanto, é preciso ter em vista algumas informações prévias. Descartes (1637/1978), pensador e articulador do pensamento moderno, vai destacar a valorização da razão e do indivíduo e a supremacia da vontade. Nas Meditações metafísicas (1641/1991), inicia por assumir uma postura metodológica de questionamento, que tem por base utilizar a dúvida como instrumento de alijamento de opiniões incertas e de fundamentação de um conhecimento seguro e indubitável. $\mathrm{Na}$ primeira meditação descreve as razões pelas quais devemos duvidar de uma série de proposições veiculadas pela tradição. Começa pela dúvida do sensível (o caráter enganoso dos juízos sensíveis), pela radicalização dessa dúvida na dúvida do sonho (indistinção entre as representações dos sonhos e as representações da vigília) e chega até a hipótese do gênio maligno e a sua extensão na dúvida metafísica do deus enganador (suspensão do critério de verdade como clareza e distinção). Descartes (1641/1991) vai paulatinamente encurtando o campo daquilo que se tomava até então como verdadeiro. Esta dúvida deve permanecer até que surjam novos fundamentos que permitam não mais duvidar. A vantagem da dúvida é que nos liberta dos preconceitos provocados pela ilusão dos sentidos. Formula, então, a Dúvida Metódica e a existência de uma única certeza: a existência do pensamento, e acaba por concluir pelo argumento do cogito (pensamento), que pressupõe que o fato de pensar torna evidente o fato de existir.

Na Segunda Meditação, a partir da certeza do cogito e da plena liberdade da alma, concebe e estabelece a distinção entre aquilo que pertence à natureza intelectual e o que pertence ao corpo. Descartes (1641/1991) justifica, então, que alma e corpo consistem em substâncias diferentes, já que podem ser concebidas pelas suas naturezas diversas e contrárias. O corpo constitui-se claramente por uma substância que permite o estabelecimento de variações de forma e de conteúdo sem ao mesmo tempo sofrer, ela mesma, tais variações. A partir da imagem de um pedaço de cera que altera todas as suas propriedades ao ser aproximada do fogo, Descartes (1641/1991) conclui que essa substância corpórea não é outra senão 
a extensão, uma vez que a extensão é a única propriedade da coisa que se mantém inalterada no momento da alteração de suas propriedades. A alma, por outro lado, é constituída pela única atividade que funda a certeza do cogito, atividade de pensamento. Como eu só sou enquanto penso, o que eu sou se confunde com a própria dinâmica de pensar: a alma é, então, uma coisa pensante, uma substância marcada pelo ação de pensar.

Na Terceira Meditação, o que está em questão é a suspensão da dúvida metafísica e o restabelecimento do critério de verdade como clareza e distinção. Para tanto, Descartes (1641/1991) precisa provar a existência de uma causa soberanamente perfeita, bela, boa e justa. Com isto, ele conquista uma possibilidade de restituir as bases do conhecimento em geral, agora de maneira efetivamente consistente.

Ele apresenta, então, na Quarta Meditação, a certeza da existência da verdade, que apenas é alcançável quando concebida de forma clara e distinta e quando nasce de um cerceamento interno da vontade humana infinita pela luz natural racionalmente determinada. Para ele, o equívoco acontece quando a vontade nos leva a afirmar ou negar algo independentemente do discernimento entre o verdadeiro e o falso. Assim, prepara-se o caminho para que o espírito se liberte dos sentidos ao encontro da verdade e supere ao mesmo tempo de uma vez por todas o movimento inicial da dúvida. Chega a afirmar que o homem pode conhecer o real de modo verdadeiro e definitivo: basta que se desenvolvam as diretrizes de um método seguro para se chegar à verdade. Busca uma certeza como base de toda a construção do conhecimento. Passa a considerar a supremacia do sujeito com relação à verdade e ao seu papel de fundamentação da certeza. Este sujeito, como uma consciência encapsulada em si mesma que se relaciona com o mundo exterior, é a gênese da moderna dicotomia entre sujeito e objeto.

Na Quinta Meditação há uma explicação da natureza corpórea e uma exposição das razões que provam a existência de Deus. Por fim, na Sexta Meditação, Descartes (1641/1991) descreve a ação do entendimento e a ação da imaginação para assim provar que são substâncias distintas, tal como o são o corpo e a alma; no entanto, por um erro dos sentidos, pensa-se comumente que são a mesma coisa.

Descartes, em uma posição otimista em relação ao progresso do conhecimento, ainda guarda a semente do sonho antigo da ciência de explicar a totalidade. Ele busca um corpo de verdades teóricas, universais e necessárias, de certezas definitivas, que não admitem erro, correção ou refutação. Descartes (1637/1978) pressupõe que o avançar da ciência possibilitaria "Livrar-nos de uma infinitude de moléstias, quer do espírito, quer do corpo, e talvez mesmo do enfraquecimento da velhice, se tivéssemos bastante conhecimentos de suas causas e de todos os remédios que a natureza nos dotou." (Descartes, 1637/1978, p. 64). Tem-se aí o sujeito absoluto, poderoso e construtor de todas as coisas consoante a sua vontade e contraposto ao mundo.

\section{A PRESENÇA DA FILOSOFIA DA SUBJETIVIDADE NAS TRÊS FORÇAS EM PSICOLOGIA: O BEHAVIORISMO, A PSICANÁLISE E PSICOLOGIA EXISTENCIAL- HUMANISTA}

As teorias em Psicologia têm como objetivo estabelecer as condições internas do eu, tomado como ponto de articulação do interior com o exterior, condições que lhe dão acesso tanto ao interno quanto ao externo. As teorias psicológicas consistem em uma descrição da estrutura e do processo deste ponto de articulação que abre a possibilidade de se refletir de maneira científica sobre o interior, sem qualquer conceito místico ou metafísico como o conceito de alma, já que a própria reflexão quebra a tendência à saída imediata e à aniquilação de si, e, assim, pode trazer à luz essa interioridade, na qual se encontra toda a verdade sobre este eu.

Para contextualizar as grandes teorias em Psicologia, bem como as práticas resultantes destas teorias, faz-se necessário destacar a manutenção, por parte das teorias psicológicas, da concepção de sujeito interiorizado, resultante do encurtamento da ideia de subjetividade, tal como assume a filosofia moderna.

A Psicologia acaba por constituir-se como ciência que se insere na modernidade, pautada no método de Descartes e no positivismo de Augusto Comte, tendo como parâmetros a objetividade, o determinismo, certezas, verdades inquestionáveis e universais, previsibilidade, superação, iluminismo progressivo, fundamento-razão. Ela mantém em sua origem a ideia de um eu interiorizado, que se constitui como sujeito intrapsíquico autofundado, tal como o denominam Sá e Rodrigues (2008). O sujeito será a substância a ser estudada pela ciência psicológica e, como tal, constitui-se de propriedades objetivas e subjetivas passíveis de mensuração ou mapeamento.

A Psicologia Científica, tentando conciliar-se com o parâmetro de objetividade, busca a sua substância, os traços de seu aparelho psíquico, de seu ser sujeito, personalidade, pessoa. Pressupõe um interior do homem repleto de emoções, instintos e do processo 
libidinoso, investigáveis em suas determinações particulares e em seus modos de interação. O problema é que a própria noção moderna de sujeito possui inconsistências. Pode-se dizer que a concepção de sujeito sofreu na modernidade um encurtamento. $\mathrm{O}$ sujeito foi sendo posicionado com amplitude totalmente diversa daquela segundo a qual ele era entendido na tradição grega até a Idade Média. Neste decurso de tempo, sujeito referia-se a todo ente, a tudo que era subjacente, de modo equivalente ao nosso sentido de sujeito gramatical. Com Descartes, a noção de sujeito passa por uma redução tal que este vai referir-se apenas ao eu suporte de todas as ações humanas e aprioristicamente constituído, ou seja, ao eu egoico. A dicotomia cartesiana consiste em, por um lado, considerar o sujeito como anterior a toda e qualquer ação e, por outro lado, o objeto como contraposto ao sujeito. Este sujeito localizável espaçotemporalmente torna-se, então, passível de mapeamento. Foi nesta mesma posição que as psicologias modernas assumiram seus estudos sobre o self humano e, constituindo-se a partir desta concepção de subjetividade, construíram a sua cartografia do sujeito, que possui propriedades e leis de funcionamento, logo se constitui como aparelho psíquico. Tal como procuraremos mostrar, porém, esse encurtamento nasce de uma desconsideração do modo de ser originário do homem e dos fenômenos ditos psíquicos que repercute sobre noções tão comuns em Psicologia como pessoa, eu, self, consciência e outras.

Para esclarecer a influência do pensamento moderno na elaboração das psicologias, descreveremos brevemente as três grandes forças em Psicologia.

As duas primeiras forças, o Behaviorismo e a Psicanálise, surgem no início do século $\mathrm{XX}$, em oposição à psicologia acadêmica, com suas concepções de consciência e introspecção. O Behaviorismo, como uma dessas forças em Psicologia, eclodiu por volta de 1913, assumindo a premissa da constituição de sujeito que, a partir do mundo, estabelece-se como elemento do qual emanam ações. Ele assume desde o princípio uma perspectiva totalmente científica e, por meio do método positivista, comprova empiricamente suas verdades elaboradas sobre esse eu, pautando-se pela ideia de que o homem é determinado por seu comportamento. O sujeito passa a ser considerado uma tábula rasa e, a partir do mundo externo, passa a experimentar a constituição de comportamentos condicionados, por meio de um processo de aprendizagem.

Watson, o primeiro expoente da perspectiva Behaviorista, mantém em seu posicionamento o rigor da ciência, suprimindo qualquer possibilidade de uma visada subjetiva acerca do psicológico. Parte ainda da dicotomia sujeito e objeto e, tomando o homem em sua objetividade, procura determiná-lo de acordo com estratégias previamente determinadas.

No Behaviorismo o psíquico é considerado como depositário dos estímulos do meio e se constitui a partir de um processo de aprendizagem e condicionamento e das leis que regulam o psiquismo: generalização e discriminação. Nas teorias Behavioristas, a subjetividade se dá de modo totalmente passivo diante dos estímulos do meio circundante e, depois de constituída, passa a ser totalmente substancializada e interiorizada, podendo também ser mapeada. Na medida em que a dualidade sujeito-mundo se estabelece, encontra-se um interior que registra comportamentos e um exterior que os produz. Watson (1930) refere-se à ação de transformação do psicólogo como consistente da elaboração de estratégias passíveis de estabelecer um dado comportamento.

A outra força em psicologia é a Psicanálise de Freud, que estabelece, a partir da noção de sujeito posicionado, um aparelho psíquico, dividindo-o em seguida em uma dinâmica consciente e uma inconsciente, as quais funcionam de acordo com as leis do psiquismo (Freud, 1895/1984). Freud opõe-se à perspectiva acadêmica que priorizava a consciência como elemento fundamental do homem e passa a priorizar a instância inconsciente na elaboração e formação do psiquismo humano. Daí surge uma espécie de determinismo psicogenético e a consideração de que as estruturas $i d$, ego e superego formam a personalidade. A clínica psicanalítica consiste em trazer à tona os motivos inconscientes que, quando impedidos de aflorar, acabam ocorrendo de modos distorcidos, por efeito dos mecanismos de defesa, encontrando-se aí a ideia de uma subjetividade nuclear que estabelece um ponto de articulação com o exterior.

A terceira força em Psicologia surgiu em meados do século $\mathrm{XX}$, opondo-se às duas primeiras $\mathrm{e}$ pretendendo superar a perspectiva moderna em Psicologia, por acreditar que as duas primeiras forças consideravam o homem como um puro e simples objeto, esquecendo-se da sua totalidade, já que, para explicá-lo, reduziam-no a conexões entre partes, e com isto retiravam do homem aquilo que the era mais caro:a sua dignidade.

Tem início, assim, na década de 30, na América do Norte, uma postura em Psicologia que se pretendia humanista, cujo líder, Abraham H. Maslow, rejeitava a posição positivista assumida 
pelo Behaviorismo, na qual o homem é constituído em uma visão naturalista, portanto, considerado como um fato ou objeto. Essa perspectiva assume uma posição humanista em que o homem é tomado como pessoa, portanto não se determina pelas leis da natureza. Além disso, ela criticava severamente os procedimentos de controle realizados por Skinner nos seus experimentos, tal como as suas conclusões determinísticas. Opõe-se, também, à construção teórica de psiquismo da Psicanálise e critica a fragmentação do psíquico e seu funcionamento por meio dos mecanismos tanto quanto a noção de causalidade fundante da estrutura psíquica

Ainda em uma tradição humanista, mantendo a ideia de que o homem deve ser assumido pela Psicologia como pessoa, encontra-se a teoria da psicoterapia de Carl Rogers (1961) em suas diferentes fases: Psicoterapia não diretiva, Psicoterapia Centrada na Pessoa e Psicologia Experiencial. Wood (1994) ressalta que, em todas as fases, Rogers coloca a relação e o respeito incondicional como os aspectos fundamentais de toda e qualquer psicoterapia, estendendo tais considerações à educação. Buys (2007, p. 343), referindo-se ao movimento humanista em sua totalidade, afirma: "O que é comum aos autores da psicologia humanista é a busca de novos modelos em relação ao humano pelo desacordo com aqueles então vigentes e com o determinismo a eles intrínseco."

Por fim, o movimento humanista ganha vulto na Psicologia no início na década de 60, tendo como principal objetivo deixar de tomar o homem como constituído por mecanismos psíquicos e por eles determinado. Ele parte da atribuição do livre-arbítrio ao homem, não se permitindo determinar nem por fatores internos nem por externos. Este se constitui mediante sua vontade e autodeterminação. Enfim, nesta perspectiva, a pessoa passa a ser respeitada como tal, pelos seus valores, intenções e pela sua identidade particular em sua totalidade

Rollo May inaugura um novo modo de pensar o homem pelo viés da Psicologia, atrelando o humanismo americano à Filosofia da Existência tal como vinha sendo pensada na Europa, abrindo as portas para o surgimento da expressão Psicologia Existencial-Humanista. Esse autor buscou focalizar a pessoa humana em sua totalidade e unicidade (Humanismo), destacando no Existencialismo a importância de temas como angústia, desamparo, liberdade e responsabilidade. May (1958/1977) referese à questão moral como centro do entendimento da existência humana. Diz que podemos entender quem somos pela busca de nossos valores e propósitos. Sem valores haveria apenas um áspero desespero.

A partir das elaborações das psicologias Existencial-Humanistas e Humanista, duas problematizações se fazem pertinentes. Parece que o modo como essas psicologias tentam resolver a questão da determinação psíquica e sua fragmentação fracassa, já que acabam por reincidir nas questões por elas criticadas, uma vez que mantêm os pressupostos metafísicos que pretendiam combater: a substancialização do sujeito e a premissa do que lhe faz bem ou mal.

Sem dúvida, a perspectiva Existencial-Humanista consistiu em um primeiro e grande esforço no sentido de pensar uma psicologia e, consequentemente, uma prática com outras bases que não fossem as científicas nem as teóricas; no entanto, essa é a nossa tese, e ainda carecia de fundamentos que lhe possibilitassem tal superação.

Com a denominação de Psicologia Fenomenológico-Existencial, pretende-se responder às questões que ficaram pendentes nesta primeira tentativa e, assim, buscar na rigorosa Fenomenologia de Husserl e na ontologia hermenêuticofenomenológica de Heidegger fundamentos para uma crítica à Psicologia que se estabeleça com os parâmetros da modernidade, quais sejam, a cisão sujeito-objeto e a sua formulação sobre o sujeito.

\section{A PROPOSTA DE HUSSERL DE UMA FENOMENOLOGIA RIGOROSA}

Em La filosofía como ciencia estricta (1910/2007), Husserl destaca a importância de se pensarem os fenômenos por meio de reflexões críticas, no lugar de se deixar levar pelas opiniões, pareceres ou posições particulares. Nesse texto o autor refere-se às duas visadas sobre os fenômenos: a do senso comum e a científica. Qualifica a visada do senso comum como confusa, ambígua e obscura, e a visada científica como uma tentativa de clarificar e tornar objetiva a visada do senso comum. Husserl aponta também as características em comum destas duas visadas: 1) a atitude natural e ingênua que tende a tomar como verdade aquilo que é visto imediatamente ou aquilo que é comprovado empiricamente; 2) o pressuposto que o eu/homem se constitui como uma substância que pode ter suas verdades confirmadas, constituindo-se como objeto com propriedades, isto é, como uma substância fechada em si mesma que se constitui dicotomicamente em relação ao mundo. Esta dicotomia acaba se estendendo à ideia de um corpo e 
de um psiquismo cujo encontro se dá em uma relação de acordo com leis universais.

$\mathrm{Na}$ atitude natural mantém o dualismo corpo e mente, concebendo-os como duas instâncias independentes e acessíveis de forma empírica e passível de mensuração, podendo ser descritos nas suas determinações causais. Cabe, então, perguntar pelas suas qualidades, suas relações causais e numéricas. Por fim, Husserl apresenta o naturalismo do comportamento científico em geral e a desconsideração da essência dos fenômenos de consciência em geral. Segundo ele, nesta perspectiva, os objetos são o que são: permanentes na sua identidade eterna, com suas qualidades determinadas quantitativamente e confirmadas ou corrigidas por novas experiências.

Husserl (2007) apresenta a atitude antinatural própria à fenomenologia como possibilidade de uma visada não comprometida com a postura ingênua que se deixa levar pela opinião já marcada por um modo de ver presente no senso comum. Nessa atitude antinatural, ao invés de se imergir em atos superpostos uns aos outros e de pressupor os objetos como dotados em si mesmos de sentidos e determinações essenciais acessíveis à pesquisa, o importante seria retornar ao ponto de gênese dos atos e ao caráter intencional de sua realização.

A atitude antinatural, tal como assumida pela Fenomenologia com seu lema fundamental "rumo às coisas mesmas", pode dar a impressão de que o que está em questão é o empírico, ou seja, é deixarse tomar pelas coisas da maneira como elas aparecem; porém a questão implica a superação de todas as tendências metafísicas que criam teorias acerca dos entes, esquecendo-se do sentido originário do ser. A orientação fenomenológica exige que se saia do campo empírico, que posiciona os objetos no espaço e no tempo, e isto envolve a necessidade de deixar o campo emergir num gesto não teorizante. Para tanto é preciso que, uma vez diante do fenômeno, se dê um passo atrás e se retorne ao seu correlato co-originário.

Husserl propõe o abandono da atitude natural por uma atitude antinatural: temos aqui a noção de epoché - a suspensão desta atitude natural. O que ele nos ensina é que precisamos deixar de tomar a verdade com referenciais e categorias hipostasiantes, como se as coisas fossem estruturadas naturalmente, dando a ideia falsa de que se conhece a verdade.

Feijoo (2009) defende que a fenomenologia se opõe frontalmente à visada teórica, já que esta tende a uma hipostasia realista ou idealista do universal. Esta atitude diante do que se apresenta é denominada por Husserl de atitude ingênиа ои natural, o que significa dizer que, com esta atitude, toma-se a natureza que se pretende investigar como se simplesmente existisse, com sentidos e determinações previamente dados e acessíveis à teoria em questão ou até mesmo ao senso comum. A superação da ingenuidade ou da atitude natural dos teóricos ocorre quando Husserl descortina a natureza intencional dos fenômenos psíquicos. O que nos interessa nesse contexto é sondar a relevância dessa posição para uma psicologia com bases fenomenológicas. Tanto na hipostasia realista quanto na hipostasia psicologizante do universal, parte-se do pressuposto de que há um eu contraposto à totalidade. No ingenuismo dos pensadores iniciais ocorria a tentativa de encontrar o ponto de conexão do eu com a totalidade. Nos pensadores modernos, a tentativa é de encontrar um "si mesmo" na estrutura própria da subjetividade. Nestas duas perspectivas do eu, este se encontra em um lugar onde se inicia o processo de rearticulação com os universais, assim como em toda e qualquer teoria parte-se de um eu que lhe dá sustentação.

$\mathrm{O}$ eu fenomenológico exige que consideremos o fato de a universalidade se constituir nos atos intencionais, portanto, se os atos intencionais forem suspensos, a universalidade desaparece e o eu fenomenológico tem uma vivência fática, real. $\mathrm{O}$ eu é considerado como fluxo que reatualiza o presente, o passado e o futuro em uma síntese de vivências que incluem lembranças e expectativas.

A Fenomenologia de Husserl e a ontologia de Heidegger parecem apontar para elementos que possibilitam a edificação de uma Psicologia Fenomenológico-Existencial em dois aspectos fundamentais: o eu como fluxo temporal, que se dá em um entrelaçamento eu-mundo, o ser-aí, como o denomina Heidegger. Para elaborar esta proposta, devem-se buscar tais fundamentos mantendo-se o rigor estabelecido por Husserl.

\section{UMA PSICOLOGIA COM BASES ONTOLÓGICO- EXISTENCIAIS}

A obra de Heidegger intitulada Ser e tempo (1927/1988) consiste em um diálogo entre a Fenomenologia hermenêutica e as ciências ônticas, para assim apresentar o seu projeto de uma ontologia fundamental. Neste projeto, Heidegger pretende levantar a pergunta acerca das condições de possibilidade das ontologias, ou seja, da própria Filosofia e, para tanto, dirige-se ao ente que pode perguntar: ser-aí. Parte da analítica existencial, que ele denomina Fenomenologia hermenêutica, assumindo para a sua descrição uma atitude antinatural, tal como postulada por Husserl, que consiste em uma supressão ou superação da tendência, presente tanto na vertente tradicional como na moderna, de pressupor que os sentidos e as determinações são dados pelas próprias coisas - no caso em questão, o 
sujeito. Pressupõe, então, que se deve deixar de tomar a verdade com referenciais e categorias, como se as coisas fossem estruturadas naturalmente, dando a ideia falsa de que se conhece a verdade. A analítica do ser-aí consiste, assim, na descrição interpretativa das estruturas ontológicas fundamentais do existir humano, explicitando a historicidade do sentido da existência em sua dimensão mais originária.

Vale ressaltar que interpretar a ontologia fundamental de Heidegger como uma filosofia da subjetividade seria um evidente equívoco, já que ele mesmo pretendia investigar ontologicamente temas como verdade, sentido, mundo, frequentemente levantados pela Filosofia. Além disso, esse filósofo refere-se à filosofia da subjetividade como carente de fundamentação, de acordo com Figal (2005). O interesse de Heidegger não recai na ideia de sujeito no sentido de um ente, e isso justamente porque, à medida que esta noção se consolida, ocorre o esquecimento do ser. A tarefa de sua ontologia consiste em buscar o sentido do ser a partir do princípio de que o ser-aí não possui nenhuma determinação que se associe essencialmente a ele: sua única determinação consiste no caráter do poder-ser. Casanova (2009a) refere-se ao mundo e à inseparabilidade homem-mundo, em que podemos encontrar o fundamento para pensar o social e o singular de modo indissociável

A proposta de Heidegger em sua obra Ser e tempo é investigar o sentido do ser e, para tanto, inicia tematizando o ente cujo ser importa a si mesmo. Denomina-o de ser-aí para destacar a sua duplicidade ente $e$ ser, que no seu fundamento estrutural ontológico se constitui como ser-no-mundo, unidade estrutural ontológica da existência do ser-aí.

$\mathrm{Na}$ primeira parte do livro Heidegger analisa fenomenologicamente a estrutura do ser-aí na sua cotidianidade, modo em que se encontra no início e na maior parte das vezes. Na busca pelo sentido do ser, Heidegger (1988, citado por Feijoo, 2010) recorre ao método fenomenológico, uma vez que não há possibilidade de redução nem de demonstração desse ser, fazendo-se necessário, então, proceder a uma espécie de mostração, de encontro do ponto de gênese da relação intencional na qual ele se mostra por si mesmo e na qual o ser-aí acompanha cooriginariamente sua mostração.

O ser-aí é um ser capaz de interrogar sobre o ser, ente privilegiado cuja inquirição recai sobre si mesmo: o próprio ser do sujeito existente. Para Heidegger, somente pelo exame fenomenológico deste existente poder-se-á chegar à noção do sentido do ser em geral. Segundo Sá (2007), Heidegger refere-se às características constitutivas do ser-aí como somente modos possíveis de ser.
Heidegger (1988) aponta para dois caracteres do ser-aí: 1) o primado da existência sobre a essência, que indica que sua essência consiste em sua existência; e 2) o ser sempre meu, que aponta para uma análise deste ente, que se acha diante de uma região fenomenal própria. É o fundamento nulo do nada que é e que, sendo, coloca em jogo o seu ser. Encontra-se, assim, marcado pela lógica do ter de ser, fundamento da responsabilidade com o seu existir, e pelo caráter do poder ser, o que caracteriza a sua incompletude ontológica.

Em virtude dos traços descritos acima, ser-aí não deve ser interpretado pela diferença de um modo determinado de existir. É preciso descobri-lo pelo modo indeterminado em que, de início e na maior parte das vezes, ele se dá: na medianidade, ou seja, na indiferença cotidiana do existir. Acaba, assim, por chegar à estrutura fundamental do ser-no-mundo. O caráter de abertura diferencia-o dos demais entes, cuja existência encontra-se fechada. O cuidado (sorge) consiste no modo como a totalidade do ser-aí sempre se desentranha em um contexto relacional, portanto, jamais isolado em si mesmo. Ser-com é sempre referido a outro ente, seja ao modo da ocupação, seja ao modo da preocupação. Heidegger prossegue sua analítica, na segunda parte de Ser e tempo (1988), ainda tendo em mente as estruturas ontológicas do ser-aí, porém em seu sentido temporal.

Por fim, em Heidegger encontraremos fundamentos que possibilitarão alcançar dois objetivos deste estudo: romper com a tutela cientificista na qual a psicologia foi construída, e com a dicotomia homemmundo, retornando à originalidade primordial na que homem e mundo são cooriginários.

\section{REPERCUSSÕES DA PERSPECTIVA FENOMENOLÓGICO-EXISTENCIAL NO SOCIAL}

Pensar hermeneuticamente acerca do horizonte histórico da constituição social, política e cultural determinante dos modos de ser na atualidade nos conduz às práticas culturais produzidas pela hegemonia das filosofias da subjetividade, as quais influenciaram diferentes posicionamentos em Psicologia. As psicologias humanistas e existencialhumanistas se estruturaram a partir de pressupostos que apontam para a cisão homem-mundo, tais como self, saúde psicológica, bem-estar, potencial humano de crescimento, autorrealização, capacidades e potencialidades exclusivas do ser humano, criatividade, amor, sentimentos, identidade, vontade, coragem, liberdade, responsabilidade, valores superiores, transcendência do ego, significados, intencionalidade, experiência subjetiva, encontro 
genuíno, entre outros. Desta forma, acabaram por promover uma acentuada ênfase no individual em detrimento do social.

A perspectiva fenomenológico-existencial, ao promover o reenraizamento da subjetividade em uma estrutura originária mais ampla, acreditamos que trouxe grandes efeitos para a psicologia pensada no âmbito do social. Essa psicologia, ao considerar a relação primeira entre homem e mundo, bem como a base co-originária de tal relação, lança elementos para uma superação dos efeitos da filosofia moderna sobre a Psicologia e o âmbito do social, já que prescinde da existência de elementos que apontem para a presença de uma interioridade ou subjetividade e considera que homem e mundo são indissociáveis. Tendo em conta a postura fenomenológica e a consideração acerca do horizonte em que nos encontramos, concluímos que a grande questão do contemporâneo consiste no total abandono e desconsideração de que tudo que angustia, entedia e atemoriza o homem se encontra naquilo que foi socialmente constituído. Assim, podemos deslocar-nos da supervalorização do individual para uma psicologia existencial que tome como foco aquilo que se constitui no âmbito do coletivo.

Heidegger, em Sérenité (1959), adverte dos perigos de uma época em que o homem, totalmente absorvido pelo domínio da técnica, que se impõe como única verdade proveniente da razão e ação humana, sob a tutela da sua vontade, esquece totalmente o sentido de sua existência, que, afinal, é sempre compartilhada. O filósofo propõe uma atitude diante do domínio da vontade técnica e ainda convoca a meditar sobre o sentido da técnica pela serenidade, ou seja, coloca-nos diante das coisas de forma desapegada, sem a intervenção do querer e da vontade subjetivas. Assim, tomando o pensamento tardio de Heidegger, pensamos edificar uma psicologia fenomenológico-existencial com ênfase no social, que consistiria, entre outras coisas, poder alcançar a descoberta das estruturas de resistência de nossa época para vislumbrar possibilidades da quebra de tais determinações.

\section{REFERÊNCIAS}

Boss, M. (1976). Análise Existencial - Daseinsanalyse: Como a Daseinsanalyse entrou na psiquiatria. Revista Daseinsanalyse, (2), 5-23.

Buys, R. (2007). A psicologia humanista. In Jacó- Vilela, \& A. L. Ferreira, \& T. T. Portugal (Orgs.), História da psicologia (pp.339348 ). Rio de Janeiro: Nau Editora.
Casanova, M. A. (2009a). Compreender Heidegger. Petrópolis, RJ: Vozes.

Casanova, M. A. (2009b). Nada a caminho. Petrópolis, RJ: Vozes.

Descartes. R. (1978). Discurso sobre o método. (J. Guinsburg, \& B. P. Junior, Trad.). São Paulo: Hemus. (Original publicado em 1637)

Descartes. R. (1991). Meditações metafísicas. (J. Guinsburg, \& B. P. Junior, Trad.). Os pensadores. São Paulo: Editora Nova Cultura Ltda. (Original publicado em 1641).

Feijoo, A. M. (2009). Clínica psicológica: filosofia e praxis. In A. M. Feijo. (Org.), Psicologia clínica e filosofia. (pp. 41-72). Belo Horizonte: Fundação Guimarães Rosa.

Feijoo, A. M. (2010). A escuta e a fala em psicoterapia: uma perspectiva fenomenológico-existencial. Rio de Janeiro: Edições Ifen.

Figal, G. (2005). Fenomenologia da liberdade. (M. A. Casanova, Trad.). Rio de Janeiro: Forense Universitária.

Freud, S. (1984). Resumo das obras completas. (J. O. Abreu, Trad.). Rio de Janeiro: Atheneu. (Original publicado em 1895)

Heidegger, M. (1988). Ser e tempo. (M. Cavalcanti, Trad.). Petrópolis, RJ: Vozes. Parte I, II. (Original publicado em 1927).

Heidegger, M. (2001). Seminários de Zollikon. (Arnhold, G., \& Prado, M. F., Trad.). Petrópolis, RJ: Vozes. (Original publicado em 1987).

Heidegger. M. (1959). Serénité. In Questions III et IV. ( André Préau, Trad.). (pp. 131-182). Paris: Gallimard.

Husserl, E. (2007). La filosofía como ciencia estricta. (E. Taberning, Trad.). La Plata: Terramar Ediciones. (Original publicado em 1910).

May, R. et al. (1977). Existencia. (C. S. Gil, Trad.) Madrid: Gredos. (originalmente publicado em 1958).

Rogers, C. (1961). Tornar-se pessoa. (M. J. Ferreira, Trad.). São Paulo: Martins Fontes.

Sá, R. N. (2007). As influências da fenomenologia e do existencialismo na psicologia. In A. M, Jacó-Vilela, Ferreira, A. L., F. T., \& Portugal. (Orgs.), História da psicologia. Rio de Janeiro: Nau Editora.

Sá, R. N., \& Rodrigues, J. T. (2008). A questão do sujeito e do intimismo em uma perpectiva fenomenológico-hermenêutica. In A. M. Feijo. (Org.), Interpretações fenomenológico-existenciais para o sofrimento psíquico na atualidade. (pp.35-54). Rio de Janeiro: Edições Ifen.

Taylor, Charles. (1997). Engaged agency and background in Heidegger. Cambridge: Cambridge Companion to Philosophy.

Watson, J. B. (1930). Behaviorism. New York: W. W. Norton.

Wood, J. (1994). Abordagem centrada na pessoa. Vitória: Fundação Ciciliano Abel de Almeida.

Recebido em 31/05/2010 Aceito em 17/09/2011

Endereço para correspondência:

Ana Maria Lopez Calvo de Feijoo. Rua Barão de Piracinunga, 62 Tijuca, CEP 20521-170, Rio de Janeiro-RJ, Brasil.E-mail: ana.maria.feijoo@gmail.com. 